IARJSET

Vol. 4, Special Issue 1, January 2017

\title{
Cell Phone Controlled Device
}

\author{
Mahesh Latte $^{1}$, Abhijit Sankpal ${ }^{2}$, Pranav Kumar Kamble ${ }^{3}$ \\ Assistant Professor, Production Department, DYPCET, Kolhapur, India ${ }^{1}$ \\ Assistant Professor, Mechanical Department, DACOE, Karad, India ${ }^{2}$ \\ Student, D.Y. Patil College of Engineering \& Technology, Kolhapur, India $^{3}$
}

\begin{abstract}
This paper represents a novel method which enables users to control their home appliances and systems from remote using a cell phone-based interface. To access the control unit, the user should send an authentication code (DTMF) along with the required/desired function/action to his/her home control system via Global System for Mobile communication (GSM). Upon being properly authenticated, the cell phone-based interface at home (control unit) would relay the commands to a microcontroller that would perform the required function/action, and return a function completion code that would be sent to the source of the original command (user's cell phone).
\end{abstract}

Keywords: Decoder, DTMF, GSM, Microcontroller, Voltage Regulator, Register.

\section{INTRODUCTION}

The aim of the proposed system is to develop a cost effective solution that will provide controlling of home appliances remotely by using cell phone. Conventionally, wireless-controlled device or appliance use RF circuits, which have the drawbacks of limited working range, limited frequency range and limited control. Use of a mobile phone for appliance control can overcome these limitations. It provides the advantages of robust control, working range as large as the coverage area of the service provider, no interference with other controllers. Though devices connected as home and office appliances consume electrical power. These devices should be controlled as well as turn on /off if required. Most of the times it was done manually. Now it is a necessity to control devices more effectively and efficiently at anytime from anywhere. In this system, we are going to develop a cell phone based home/office appliance controller. This system is designed for controlling arbitrary devices; it includes a cell phone which is connecting to the system via head set. To active the cell phone unit on the system to call is to be made and as the call is answered automatically, in response to access the system to control devices. As the caller press the specific password, it results in turning ON or OFF specific device. The device switching is achieved by Relays [8]. By using this system we have to operate home or office appliances automatically.

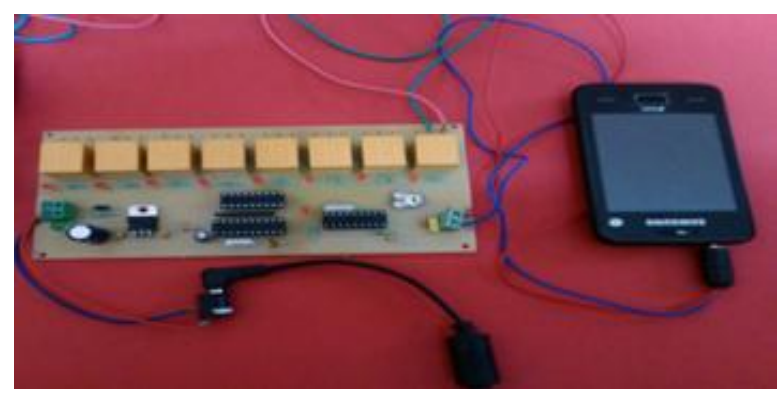

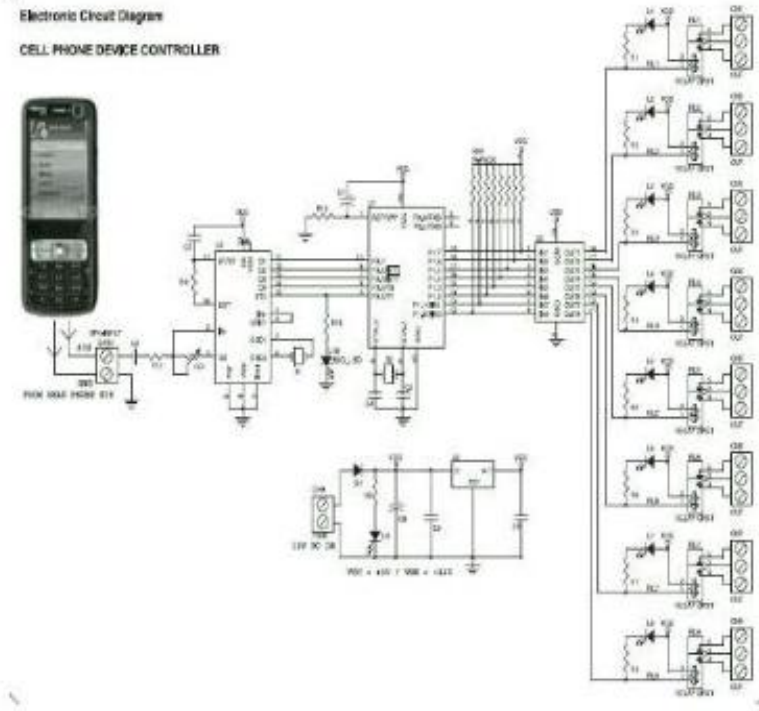

Fig 1. Circuit diagram of device

\section{WORKING}

In this device, the appliance is controlled by a mobile phone that makes a call to the mobile phone attached to the interface circuits. In the course of a call, if any button is pressed, a tone corresponding to the button pressed is heard at the other end of the call. This tone is called 'dualtone multiple-frequency' (DTMF) tone. The controller perceives this DTMF tone with the help of the phone stacked in the projects.

The received tone is processed by the AT89 $x x x$ microcontroller with the help of DTMF decoder MT8870. The decoder decodes the DTMF tone into its equivalent binary digit and this binary number is sent to the microcontroller. The microcontroller is preprogrammed to take a decision for any given input and outputs its decision 
to relay drivers (ULN2803) in order to drive the relays for on or off to control the appliance.

The mobile that makes a call to the mobile phone stacked in the controller circuits (Receiver) acts as a remote. So this simple project does not require the construction of receiver and transmitter units. DTMF signaling is used for telephone signaling over the line in the voice frequency band to the call switching centre. The version of DTMF used for telephone tone dialing is known as "Touch-Tone." DTMF assigns a specific frequency (consisting of two separate tones) to each key so that it can easily be identified by the electronic circuit. The signal generated by the DTMF encoder is a direct algebraic summation, in real time, of the amplitudes of two sine (cosine) waves of different frequencies, i.e., pressing ' 5 ' will send a tone made by adding $1336 \mathrm{~Hz}$ and $770 \mathrm{~Hz}$ to the other end of the line.

\section{PART LIST (CELL PHONE CONTROLLED DEVICE)}

1. R1 9 - 1K [BROWN,BLACK, RED](9 NOS)

2. R10 - 220E [RED, RED, BROWN]

3. R11 - 270K [RED,VIIOLET, YELLOW]

4. R12 - 22K [RED,RED, ORANGE]

5. R13 - 10K [BROWN,BLACK,ORANGE]

6. RN1 - 10K ;V 9 Pin Resistor bank (R-Pack)

7. C1 - 10UF / 16V Electrolytic

8. C2, 8, 9 - 100KPF DISC(0.1UF / 104) (3 NOS)

9. C3 - 100KPF POLY (0.1UF / 104)

10.C4, 5 - 33PF Ceramic Disc (2 NOS)

11.C6 - 1000UF / 16V Electrolytic

12.X1 - 3.579545 MHZCrystal

13.X2 - 11.0592 MHZCrystal

14.D1 - 1N4007Diode

15.L1 8, 10 - 3 mm OR 5 mm RED LED (9 NOS)

16.L9 - 3 mm OR5 mm GREEN LED

17.U1 - AT89C2051- MICROCONTROLLER (Pre Programmed MCU)

18.U2 - MT8870 - DTMF DECODER

19. U3 - ULN2803- Relay Driver

20. U4 - LM7805 - +5V Voltage Regulator

21. CN10 - 2 PIN SCREW TERMINALS BLOCK

22. 1 nos. - 20 PIN IC SOCKET FORU1

23.2 nos. - 18 PIN IC SOCKET FORU2 and U3

24.1 nos. - Standard NOKIA Head phone

25.CN1 $\sim 8$ - 3 PIN SCREW TERMINALS BLOCK (8 NOS) ¡V not included in kit

26. CN9 - 2 PIN SCREW TERMINALS BLOCK ;V not included in kit On board Power LED (Green) indicator

\section{MICROCONTROLLER (AT89C2051)}

A microcontroller is a computer on a single chip; it contains a CPU (usually called the core) and a variety of peripherals which assist your application. The AT89C2051is a low-voltage, high-performance CMOS 8bit microcomputer with $2 \mathrm{~K}$ bytes of Flash programmable and erasable read-only memory (PEROM). By combining a versatile 8-bit CPU with Flash on a monolithic chip, the
Atmel AT89C2051 is a powerful microcomputer which provides a highly-flexible and cost-effective solution to many embedded control applications.

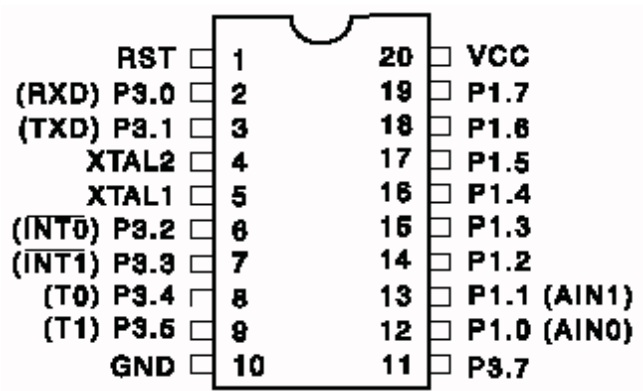

Fig 2. Pin diagram of micro-controller

\section{DTMF DECODER}

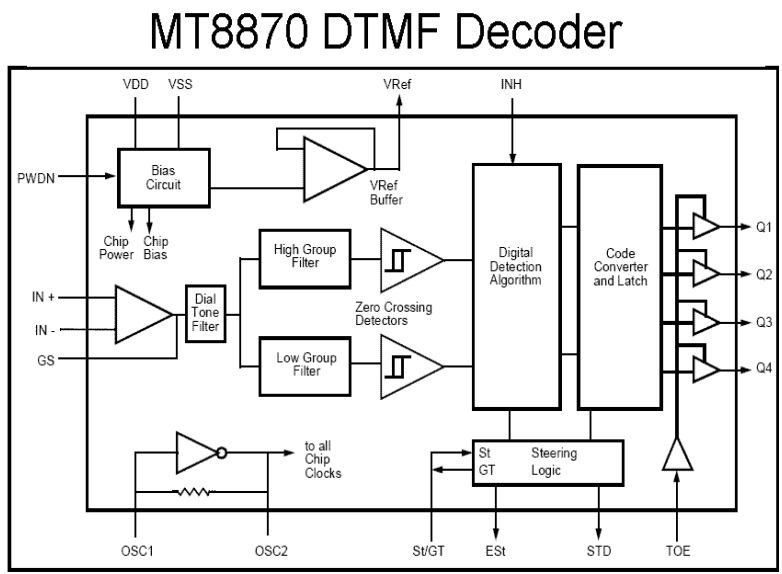

Fig 3. Functional diagram of DTMF Decoder

An MT8870 series DTMF decoder is used here. All types of the MT8870 series use digital counting techniques to detect and decode all the 16 DTMF tone pairs into a 4-bit code output. The built-in dial tone rejection circuit eliminates the need for pre-filtering. When the input signal given at pin 2 (IN-) in single-ended input configuration is recognized to be effective, the correct4-bit decode signal of the DTMF tone is transferred to Q1 (pin 11) through Q4 (pin 14) outputs. The DTMF decoder decodes the tone into its equivalent binary digit and this binary number is sent to the microcontroller.

\section{RELAY DRIVER}

Why not just directly connect the outputs of the micro controller to the relays. The answer is that the micro controller pins would burn out with the $12 \mathrm{~V}$ being applied to them. A relay driver IC is required. The most commonly available driver chip which ULN2803, we are used. A single pole dabble throw (SPDT) relay is connected to port P1.0 to P1.7 of the microcontroller through a Relay driver IC (ULN2803). The relay requires 12 volts at a current of around $100 \mathrm{ma}$, which cannot provided by the micro controller. So the driver IC is added. The relay is used to operate the external high Voltage Load or appliance or any other electrical device. 
Vol. 4, Special Issue 1, January 2017

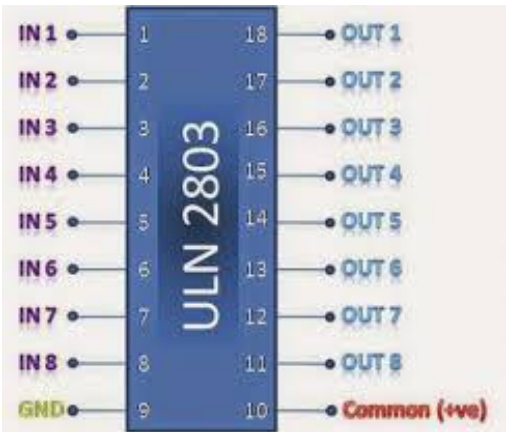

Fig 4. Relay driver Circuit

\section{LM7805 (3 TERMINAL VOLTAGE REGULATER)}

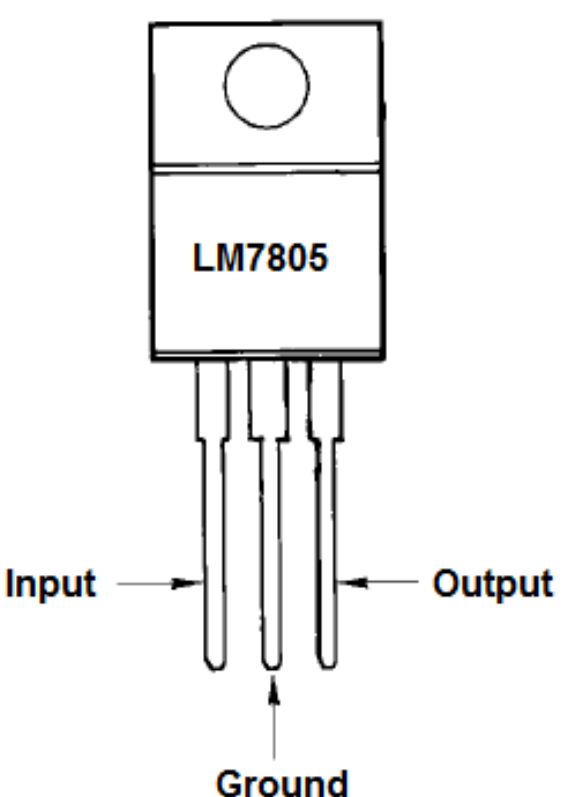

Fig 5. LM7805 3 Terminal Voltage Regulater

This is used to make the stable voltage of $+5 \mathrm{~V}$ for $\mathrm{U} 1$ and U2 (MCU).The LM7805 is three terminal positive regulators are available in the TO-220/D-PAK package and with several fixed output voltages, making them useful in a wide range of applications. Each type employs internal current limiting, thermal shut down and safe operating area protection, making it essentially indestructible. If adequate heat sinking is provided, they can deliver over $1 \mathrm{~A}$ output current. Although designed primarily as fixed voltage regulators, More information please refer Data sheet Of LM7805

\section{CRYSTAL OSCILLATOR}

A crystal oscillator is an electronic circuit that uses the mechanical resonance of a vibrating crystal of piezoelectric material to create an electrical signal with a very precise frequency. This frequency is commonly used to keep track of time (as in quartz wristwatches), to provides stable clock signal for digital integrated circuits, and to stabilize frequencies for radio transmitters/ receivers.

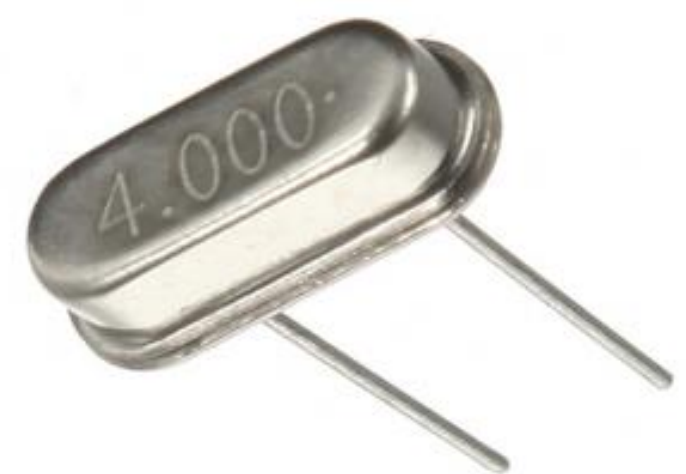

Fig 6. Crystal Oscillator

IX. SPDT RELAY (12V)

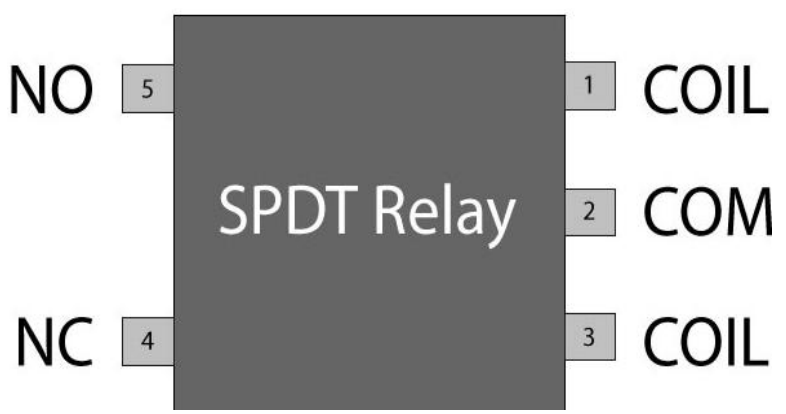

Fig 7. SPDT Pin out diagram

It closes the voltage less point of contact while the remote control works to control the equipment outside. The relay takes advantage of the fact that when electricity flows through a coil, it becomes an electromagnet. The electromagnetic coil attracts a steel plate, which is attached to a switch. So the switch's motion (ON and OFF) is controlled by the current flowing to the coil, or not, respectively. A very useful feature of a relay is that it can be used to electrically isolate different parts of a circuit. It will allow a low voltage circuit (e.g. 5VDC) to switch the power in a high voltage circuit (e.g. 100 VAC or more). The relay operates mechanically, so it cannot operate at high speed

\section{PROGRAMMING OF MICROCONTROLLER (FOR ON AND OFF A DEVICE PASSWORD)}

The MT8870 decodes the received tone and sends the equivalent binary number to the microcontroller. According to the program in the microcontroller, the eight relays 'on' or 'off'.

\section{For ON}

Press key '11' = relay 1 on Press key '21' = relay 2 on Press key ' 31 ' = relay 3 on Press key ' 41 ' $=$ relay 4 on Press key '51' = relay 5 on Press key '61' = relay 6 on Press key '71' = relay 7 on Press key ' 81 ' = relay 8 on 


\section{For OFF}

Press key '10' = relay 1 off

Press key '20' = relay 2 off

Press key ' 30 ' = relay 3 off

Press key ' 40 ' $=$ relay 4 off

Press key ' 50 ' = relay 5 off

Press key '60' = relay 6 off

Press key '70' = relay 7 off

Press key ' 80 ' = relay 8 off

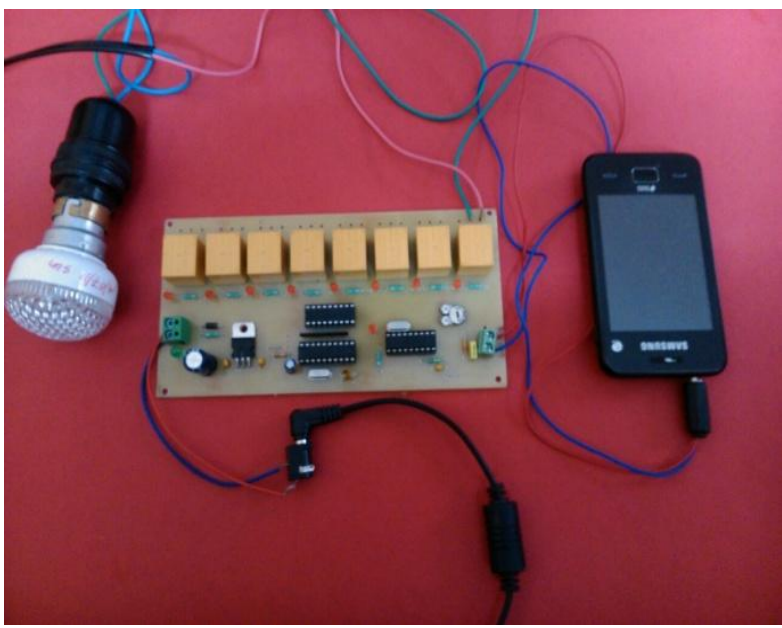

Fig 8. Cell phone controlled device

\section{CONCLUSION}

In this paper we have described the concept of em- bedded information about use of cell phone how to control the home or office appliances. The systems can be used as a test bed for any application that requires on-off switching based applications. Wireless controlled home appliances in the comforts of any environment will revolutionize our way of living. Controlling appliances remotely by a cell phone will one day become a reality.

\section{REFERENCES}

[1] W.Bolton, Mechatronics 3/e (2003) III edition (Addison Wesley) ISBN 81-7758-284-4

[2] David G. Alciatore \& Michael B. Histand, Introduction to Mechatronics \& Measurement System (2011) (TMH) ISBN 0-07052908.

[3] N.P.Mahalik , Mechatronics Principles, Concepts \& Applications (2008), (TMH) ISBN 0-07-0483744.

[4] Channakesava R. Alavala, CAD/CAM-Concepts \& Applications, (PHI)

[5] Singh, M.D. \& Joshi J.G, Mechatronics,. (EEE) (PHI) (2006- ISBN 81-203-2986-4.

[6] Dan Necsulescu, Mechatronics, (Pearson Education) ISBN 81-7808 $-676-\mathrm{X}$.

[7] Ogata, Modern Control Engineering (2010) (Pearson Education), ISBN 81-7808-579-8

[8] Eric Min-yang Wang, Stone Shao-yung Shih (2009), "A Study on Thumb and Index Finger Operated Interface for Personal Mobile Devices: Mobile Phone Keypad and Joystick" IEEE, ISSN 978-14244-3672-9/09.

[9] D. Mayl, C. Terkowskyl, T. HaerteP and C. Pleul,(2012) "Using EPortfolios to support experiential learning and open the use of teleoperated laboratories for mobile devices"IEEE, ISSN 978-1-46732542-4/12.

\section{BIOGRAPHY}

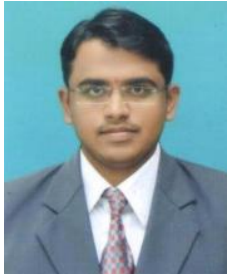

Mahesh Latte is presently working as an Asst. Prof. at DYPCET, Kolhapur. He completed his bachelor's degree from JJMCOE, Shivaji university. He then completed Master's from RIT, Islampur (Autonomous Institute) with Gold Medal in Production engineering. He published 1 paper in international journal \& 5 papers in National Conferences . His area of interest \& research is Industrial Engineering \& Manufacturing \& Mechatronic Systems. 